\title{
Revista de Medicina y Cine: 15 años de aprendizaje compartido
}

\author{
Irene CAMBRA BADII
}

\section{Journal of Medicine and Movies: 15 years of shared learning}

\author{
Universitat de Vic - Universitat Central de Catalunya. Grupo de Investigación en Educación en Ciencias de la Salud (GRECS) del Departamento de Ciencias \\ Experimentales y de la Salud, Universitat Pompeu Fabra (Barcelona, España).
}

Autor para correspondencia: Irene Cambra Badii. Correo electrónico: irenecambrabadii@gmail.com

Recibido el 20 de junio de 2019; aceptado el 25 de junio de 2019.

Cómo citar este artículo: Cambra Badii I. Revista Medicina y Cine: 15 años de aprendizaje compartido. Rev Med Cine [Internet] 2019;15(4):201-2. DOI: http://dx.doi.org/10.14201/rmc2019154201202

Sin lugar a dudas, la Revista Medicina y Cine es uno de los espacios académicos que mejor combina la calidad científica con el interés personal y profesional. ¿Qué significa esto? En primer lugar, que es una revista prestigiosa que incorpora nuevas metodologías y fuentes de discusión sobre la necesaria articulación entre la medicina y las demás ciencias de la salud, con manifestaciones artísticas como la literatura, el cine y las series de televisión. En segundo lugar, que todos, absolutamente todos los artículos publicados, revisten de gran interés para la comunidad científica y social. Nos hemos informado sobre variedad de temas: enfermedades infecciosas, autoinmunes, cardiovasculares, dermatológicas, genéticas, respiratorias, enfermedades mentales, pediátricas y afecciones extrañas; hemos aprendido acerca de sus diagnósticos y tratamientos, los errores y los éxitos profesionales; nos hemos detenido a analizar las representaciones sobre los profesionales de la salud y los distintos puntos de vista sobre las enfermedades y los tratamientos; nos hemos acercado nuevas propuestas docentes, en algunos casos resultados del trabajo en cursos de medicina luego de más de diez años de trabajo continuo... Hemos aprendido con el cine y con la literatura. Hemos aprendido con la experiencia de los profesionales a través de su mirada sobre las películas y las obras literarias. Hemos aprendido en diálogo con otros.

Creo que esto último no debe pasar desapercibido en una revista científica. De alguna manera, la consolidación de la Revista Medicina y Cine guarda relación con la calidad de sus publicaciones y con la innovación que representan, pero también con el tono ameno y entretenido de sus propuestas. Aprendemos disfrutando.
Aprendemos encontrando puntos en común en distintos artículos, que dialogan entre sí: podemos fijarnos en la variedad de artículos publicados sobre Frankenstein, por ejemplo1-4, o en las distintas miradas sobre películas clásicas como Despertares 5,6 .

El diálogo implícito que establecen estos artículos en los distintos números que alimentan estos quince años de publicaciones enriquece y complejiza la mirada, evidentemente interdisciplinaria, sobre problemáticas nuevas y muchas veces difíciles de resolver.

Desde un punto de vista personal, quiero enfatizar dos cuestiones que supone para mí la Revista Medicina y Cine. En primer lugar, tal como venía diciendo, se trata de la jerarquización académica de la articulación entre las ciencias de la salud y las manifestaciones artísticas como el cine y la literatura. Esta articulación es muchas veces menospreciada -en pos de ciertos criterios rígidos de comprensión de la ciencia y de la metodología de la investigación. Sin embargo, a través de la Revista Medicina y Cine accedemos a ideas nuevas que nos brindan la posibilidad de entender, una y otra vez, la importancia de las artes en la vida humana en general, y la necesidad de incorporar las humanidades en medicina y en todas las ciencias de la salud y de la vida. Esta inestimable contribución a la formación de profesionales y a la discusión de temas que produce la Revista Medicina y Cine con la difusión de artículos de interés profesional merece la pena ser destacada.

Por otra parte, cabe aquí contar una anécdota personal. Conocí la revista allá por el año 2010, cuando 
comenzaba mis pasos en la investigación con una beca de la Secretaría de Ciencia y Técnica de la Universidad de Buenos Aires, a cargo de Juan Jorge Michel Fariña, quien se ha dedicado durante más de veinticinco años al estudio de la ética y el cine, con variadas y renovadas metodologías. Para mí el cine siempre ha sido un universo fascinante, y poder trabajar con películas y series fue no sólo un enorme desafío profesional sino también un gran disfrute. Como decían mis amigos, curiosos por mis intereses: "isiempre te gusta ver películas de enfermedades o médicos!". Por tal razón utilicé las ocho temporadas de Doctor House para mi tesis doctoral y aún vuelvo a mirar aquellos episodios.

Trabajando en la Universidad de Buenos Aires, Argentina, nos encontramos con la Revista Medicina y Cine gracias a los buscadores de internet, y nos sorprendimos al encontrar una revista prestigiosa y de calidad que aceptara publicar artículos con una mirada cualitativa, como era nuestro enfoque sobre las películas. El análisis narratológico, centrado en la historia, los personajes, los detalles de la trama, era valorado tanto en nuestros artículos como en otros, que leíamos con sumo interés. En esos años combiné el seguimiento exhaustivo de los artículos de la Revista con la publicación de mis propios artículos, realizados con otras colegas y becarias con quienes disfrutamos el trabajo conjunto ${ }^{7-8}$.

Fue en ese tiempo de lectura "a la distancia" que conocí los trabajos de Josep-Eladi Baños y Jordi Pérez en la Universitat Pompeu Fabra de Barcelona, y las propuestas de María Teresa Icart Isern en la Universidad de Barcelona y de Magí Farré en la Universitat Autónoma de Barcelona. Seguí sus publicaciones hechas en otras revistas y encontré grandes puntos en común. No se imaginan la alegría de poder encontrar distintos equipos que tengan miradas similares, o incluso complementarias, sobre una metodología de trabajo con el cine y la literatura.

Años más tarde, en 2018, tuve la oportunidad de hacer una estancia de investigación post-doctoral en el Grupo de Investigación sobre Educación en las Ciencias de la Salud (GRECS) en la Universitat Pompeu Fabra, bajo la dirección de Josep-Eladi Baños y con la grata compañía de Jordi Pérez. Una nueva sorpresa: aquellas personas que yo había leído durante tantos años tenían un rostro que iba haciéndose más familiar día tras día. El nombre de autor (que, al decir de Michel Foucault, no se refiere al nombre propio ordinario sino que más bien es un concepto de una posición de autoría en un campo discursivo ${ }^{9}$ ) era entonces articulado a una persona de carne y hueso que iba fundiéndose con una experiencia de trabajo amena y de calidad, que cambió mi devenir profesional y me permitió instalarme en Vic, Barcelona, para continuar trabajando con estos temas y metodologías.

A través de Jordi Pérez, quien se ha convertido en un gran amigo, tuve la preciosa oportunidad de visitar Salamanca y conocer personalmente a Enrique García Sánchez, con quien pude comenzar a colaborar en la difusión de la revista. Especial mención merecen entonces los dos editores, tanto Enrique como José Elías García Sánchez, quienes llevan a cabo una labor inestimable. En muchas ocasiones no nos damos cuenta el inmenso trabajo que conlleva editar una revista académica, recepcionar los artículos, enviarlos a evaluación de pares, editarlos; trabajo que hacen con amor y esmero, con cuidado hacia los autores y hacia los lectores. Las fotos de portada de Salamanca nos enseñan también detalles de la ciudad donde está radicada la revista, enfatizando una vez más la importancia del contexto, de la historia, de las imágenes. Aprendemos también con estos detalles.

¡Va entonces mi agradecimiento por el aprendizaje de estos primeros quince años de la Revista, y los mejores deseos de felicidad para los que vienen!

\section{Referencias}

\footnotetext{
1. De Prada Pérez F. Manipulación genética: el nuevo monstruo de Frankenstein en el cine. Rev Med Cine 2008; 3(2):68-75.

2. Baños Díez J, Aramburu Beltrán J, Sentí-Clapés M. Biocinema: la experiencia de emplear películas comerciales con estudiantes de Biología. Rev Med Cine 2008; 1(2): 42-6.

3. Baños J, Rodríguez G. Frankenstein: un mito más allá del cine de ciencia ficción. Rev Med Cine 2014; 10(1):37-44.

4. Baños J, Guardiola E. En el bicentenario de Frankenstein; or, The Modern Prometheus: Mucho más que una novela gótica de terror. Rev Med Cine 2018; 14(3): $155-7$

5. Jiménez Serranía M. Despertares (1990): la epidemia de los niños que se quedaron dormidos. Rev Med Cine 2008; 3(3):102-12.

6. Pérez-Sánchez J. El uso de la película Despertares (1990) para evaluar aprendizajes en la licenciatura de Biología de la Universidad Pompeu Fabra. Diez años de experiencia. Rev Med Cine 2009;5(1):27-9.

7. Cambra-Badii I, Ormart E. La bioética en el escenario de las tecnologías de reproducción humana asistida. Rev Med Cine 2014;10(4):164-73.

8. Cambra-Badii I, Mastandrea P, Paragis P. El mandato del nacimiento. Cuestiones bioéticas y biopolíticas en la serie El cuento de la criada. Rev Med Cine 2018; 14(3): 181-91.

9. Foucault M. Qu'est-ce qu'un auteur? Bull Soc Franç Phil. 1969;63(3):73-104.
}

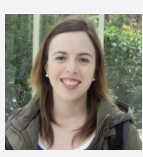

Irene Cambra Badii. Doctora en Psicología, docente e Investigadora en la Universitat de Vic - Universitat Central de Catalunya, e investigadora del Grupo de Investigación sobre Educación en Ciencias de la Salud, Universitat Pompeu Fabra, Barcelona. Ha sido docente e investigadora por más de diez años en la Universidad de Buenos Aires, Argentina. 